\title{
Subclavian transcatheter aortic valve implantation (TAVI): superficial cervical plexus block combined with low-dose interscalene block
}

\section{Remplacement valvulaire aortique percutané (TAVI) sous- clavier : combinaison d'un bloc du plexus cervical superficiel à un bloc interscalénique à faible dose}

\author{
Vivian Ip, MBChB, FRCA (1) - Blaine Achen, MD, FRCPC · Jeevan Nagendran, MD, \\ PhD, CIP, FRCSC
}

Received: 21 April 2020/Revised: 20 May 2020/Accepted: 7 July 2020/Published online: 14 July 2020

(C) Canadian Anesthesiologists' Society 2020

\begin{abstract}
Purpose Transcatheter aortic valve implantation (TAVI) has become a widely used technique for treating aortic stenosis. Subclavian access may be warranted in the presence of poor vasculature that precludes femoral access. Conscious sedation is increasingly being adopted with some evidence suggesting better outcomes compared with those of general anesthesia. We describe the use of two regional anesthetic techniques to facilitate subclavian access for TAVI.

Clinical features Our case report involves the successful management of a challenging patient with severe peripheral vasculopathy and respiratory compromise undergoing a trans-subclavian TAVI. Surgical anesthesia was provided by low-dose local anesthetic titrated via an interscalene perineural catheter and a single-shot superficial cervical plexus block while preserving respiratory function.

Conclusions The interscalene catheter in situ allowed for low-dose local anesthetic titration without further jeopardizing the pulmonary function throughout the procedure. Unlike other interfascial plane blocks, combined low-dose superficial cervical plexus and interscalene brachial plexus blocks offer surgical
\end{abstract}

V. Ip, MBChB, FRCA $(\varangle) \cdot$ B. Achen, MD, FRCPC

Department of Anesthesia and Pain Medicine, University of

Alberta Hospital, Edmonton, AB, Canada

e-mail: hip@ualberta.ca

J. Nagendran, MD, PhD, CIP, FRCSC

Department of Cardiothoracic Surgery, Mazankowski Alberta

Heart Institute, Edmonton, AB, Canada anesthesia and limb immobility, thus providing optimal condition for subclavian TAVI to be performed with minimal sedation.

\section{Résumé}

Objectif Le remplacement valvulaire aortique percutané (TAVI) est devenu une technique très répandue pour le traitement de la sténose aortique. En présence d'une maladie vasculaire périphérique excluant un accès fémoral, un accès par voie sous-clavière pourrait être justifié. La sédation consciente est de plus en plus privilégiée, certaines données probantes suggérant de meilleurs devenirs par rapport à l'anesthésie générale. Nous décrivons l'utilisation de deux techniques d'anesthésie régionale visant à faciliter l'accès sousclavier pour un TAVI.

Éléments cliniques Notre présentation de cas relate la prise en charge réussie d'un patient complexe atteint de vasculopathie périphérique sévère et d'insuffisance respiratoire subissant un TAVI par voie trans-sousclavière. L'anesthésie pour la chirurgie a été réalisée à l'aide d'anesthésique local à faible dose, titré via un cathéter périnerveux interscalénique, et d'un bloc $d u$ plexus cervical superficiel par injection unique, afin de préserver la fonction respiratoire.

Conclusion Le cathéter interscalénique in situ a permis la titration de l'anesthésique local à faible dose sans compromettre la fonction pulmonaire tout au long de l'intervention. Au contraire d'autres blocs du plan interfascial, la combinaison d'un bloc du plexus cervical superficiel à un bloc du plexus brachial interscalénique à faible dose offre une anesthésie chirurgicale et une 
immobilité du membre visé, créant ainsi les conditions optimales à la réalisation d'un TAVI sous-clavier sous sédation minimale.

Transcatheter aortic valve implantation (TAVI) has become a widely used technique for treating aortic stenosis. The procedure allows a prosthetic aortic valve loaded onto a catheter to be deployed through a cutdown or percutaneous access, most commonly via the femoral artery. Nevertheless, subclavian access may be warranted if poor vasculature precludes femoral access. ${ }^{1}$ Conscious sedation is increasingly being adopted with some evidence suggesting better outcomes compared with general anesthesia, in part because of reduced inotropic support, improved efficiency, less delirium, as well as a trend towards reduced pulmonary complications. ${ }^{2-4}$ Compared with transapical or transaortic approaches, subclavian approaches have recently shown good outcomes including improved 30-day mortality and length of stay. ${ }^{5}$ Nevertheless, a higher stroke rate has been reported, possibly due to the right carotid artery being jeopardized as the TAVI catheter traverses the innominate artery. ${ }^{5}$ Nonetheless, effective regional anesthesia providing surgical anesthesia with minimal sedation allows the neurologic status to be monitored intraoperatively. Herein, we report a trans-subclavian TAVI performed under low-dose regional anesthesia and minimal sedation.

\section{Case}

A 72-yr-old man (who consented to this report) with a history of coronary artery disease, peripheral vascular disease, type- 2 diabetes, atrial fibrillation, hypertension, and severe aortic valve stenosis was scheduled for TAVI using a trans-subclavian approach because of calcified atherosclerotic iliac vasculature. The procedure accessed the left subclavian artery via direct cutdown just medial to the deltopectoral groove, allowing a 6-Fr sheath to be inserted. A regional technique was chosen to anesthetize the nerves that provide cutaneous innervation to the anterolateral neck and infraclavicular region, as well as motor supply to the arm. A combination of single-injection superficial cervical plexus block (SCPB) and interscalene brachial plexus block (IBPB) were planned. Nevertheless, since the patient required $30^{\circ}$ head-up positioning because of orthopnea with oxygen saturation at $94 \%$ on air, a perineural catheter was placed for the IBPB rather than a single-shot nerve block. This allowed titration of low volume local anesthetic (LA) to minimize further respiratory compromise from phrenic nerve block secondary to IBPB. Monitoring was consistent with published guidelines ${ }^{6}$ and $2 \mathrm{~L}$ of oxygen was given via a nasal cannula.

The SCPB was performed at C6 vertebral level using a high-frequency linear transducer (HFL 50 × 6-15 MHz, Sonosite Edge, Bothwell, WA, USA). Adopting a lateral to medial in-plane approach using a 22-G insulated nerve block needle, $10 \mathrm{~mL}$ of LA (3:1 ratio of $2 \%$ lidocaine: $0.5 \%$ bupivacaine) was injected deep to the sternocleidomastoid muscle, between the deep cervical fascia and the prevertebral fascia. Importantly, the needle did not pierce through the prevertebral fascia and thus avoided the phrenic nerve. This was followed by IBPB catheter insertion with the same transducer. A 21-G, 50-mm catheter-over-needle unit (Multiset UPK NanoLine, Pajunk, Germany) was inserted in an out-of-plane approach, with the catheter positioned posterior to the plexus to limit the amount of LA spreading anteriorly towards the phrenic nerve. Only $5 \mathrm{~mL}$ of the LA solution was injected. The catheter was secured in place and the patient did not complain of dyspnea and the oxygen saturation was maintained at $99 \%$ on $2 \mathrm{~L}$ of oxygen via nasal cannula. The sensory block was assessed using perception of temperature change with ice, and the anesthetized area included the left anterior neck and shoulder, covering the inferior portion of the clavicle at C3 to C6 dermatomes, together with motor blockade of the arm.

Intraoperatively, fentanyl $100 \mu \mathrm{g}$ and midazolam $1 \mathrm{mg}$ were given intravenously, and $2 \mathrm{~mL}$ of the LA mixture was titrated via the IBPB catheter prior to skin incision and again towards the end of the procedure. A 26-mm Sapien S3 valve (Edwards Lifesciences, Irvine, CA, USA) was successfully deployed over the existing diseased valve under fluoroscopic guidance. The patient was rousable throughout surgery, obeyed commands, and remained comfortable. The TAVI duration was $1.5 \mathrm{hr}$ and the patient was transferred to the intensive care unit for postoperative monitoring. Post-procedural pain was generally mild; therefore, the perineural catheter was removed without initiating continuous LA infusion. He required $650 \mathrm{mg}$ of acetaminophen and $0.4 \mathrm{mg}$ hydromorphone subcutaneously to maintain a numeric rating scale of $<4$ out of 10 .

\section{Discussion}

This report highlights the successful management of a patient with severe peripheral vasculopathy and respiratory compromise undergoing a trans-subclavian TAVI utilizing low-dose regional anesthesia with an IBPB and SCPB. This 
was a clinically challenging case because of the need to preserve respiratory function without compromising nerve block quality to provide adequate surgical anesthesia. Because the risk of phrenic nerve palsy is high with an interscalene block, the use of low-dose LA can reduce the risk of hemidiaphragmatic paresis. ${ }^{7,8}$ With the interscalene catheter in situ, a small volume of LA can be titrated as needed without further jeopardizing the pulmonary function throughout the procedure. Furthermore, should phrenic nerve palsy occur, a washout technique using normal saline via the IBPB catheter has been described to dilute the LA and rapidly regain respiratory function should it become necessary. ${ }^{9}$ Although unnecessary in this case, if LA infusion is required postoperatively via the IBPB for respiratory compromised patients, lidocaine infusion could be considered for its beneficial quick offset property. Parameters such as respiratory rate, use of accessory muscles, and continuous oxygen saturation should be vigilantly monitored.

The benefits of an interscalene catheter should be considered compared with a single-injection technique. Being technically more difficult, it is prudent for anesthesiologists skilled in regional anesthesia to insert the perineural catheter in close proximity to the brachial plexus to allow for successful low volume LA block. This remains true for the SCPB also, where meticulous deposition of LA above the prevertebral fascia is necessary to reduce undesirable LA spread towards the phrenic nerve.

Previous case series have described the use of pectoralis interfascial plane block alone ${ }^{10}$ or in combination with high-volume interscalene block for patients undergoing trans-subclavian TAVI. ${ }^{11}$ Interfascial blocks are generally less technically challenging; nonetheless, without specifically injecting LA adjacent to the neural structures, large volumes of LA are required, which may increase the risk of LA toxicity in patients with poor cardiac function contributing to reduced drug clearance. ${ }^{12}$

Given the increased incidence of stroke with transsubclavian TAVI, adequate surgical anesthesia with minimal sedation allows the neurologic status to be monitored during the procedure, as seen in our case. A reliable, reproducible clinical effect is necessary for regional techniques serving as surgical anesthesia because of complications caused by deep sedation, such as airway obstruction, hemodynamic instability, or non-compliance.

In summary, our unique case successfully showed that a combination of SCPB and low-dose IBPB provides surgical anesthesia for TAVI via a subclavian approach. With meticulous LA titration of perineural IBPB, respiratory function was preserved while maintaining the quality of surgical anesthesia. Collaboration with the surgical team and anesthesiologist providing intra- procedure care, as well as the acute pain service was also paramount for a successful outcome. Further research is warranted to investigate the value of this alternative regional anesthesia techniques in high-risk populations.

Author contributions Vivian Ip contributed to all aspects of this manuscript, including conception and drafting and revising the article. Blaine Achen and Jeevan Nagendran contributed to conception and revising the article.

Disclosures None.

Funding statement None.

Editorial responsibility This submission was handled by Dr. Hilary P. Grocott, Editor-in-Chief, Canadian Journal of anesthesia.

\section{References}

1. Ramlawi B, Anaya-Ayala JE, Reardon MJ. Transcatheter aortic valve replacement (TAVR): access planning and strategies. Methodist Debakey Cardiovasc J 2012; 8: 22-5.

2. Miles LF, Joshi KR, Ogilvie EH, et al. General anaesthesia vs. conscious sedation for transfemoral aortic valve implantation: a single UK centre before-and-after study. Anaesthesia 2016; 71: 892-900.

3. Abawi M, Nijhoff $F$, Agostoni $P$, et al. Incidence, predictive factors, and effect of delirium after transcatheter aortic valve replacement. JACC Cardiovasc Interv 2016; 9: 160-8.

4. Goren $O$, Finkelstein A, Gluch A, et al. Sedation or general anesthesia for patients undergoing transcatheter aortic valve implantation-does it affect outcome? An observational singlecentre study. J Clin Anesth 2015; 27: 385-90.

5. Dahle TG, Kaneko T, McCabe JM. Outcomes following subclavian and axillary artery access for transcatheter aortic valve replacement: Society of the Thoracic Surgeons/American College of Cardiology TVT Registry Report. JACC Cardiovasc Interv 2019; 12: 662-9.

6. Dobson G, Chow L, Flexman A, et al. Guidelines to the practice of anesthesia - revised edition 2019. Can J Anesth 2019; 66: 75108.

7. Lee JH, Cho SH, Kim SH, et al. Ropivacaine for ultrasoundguided interscalene block: $5 \mathrm{~mL}$ provides similar analgesia but less phrenic nerve paralysis than $10 \mathrm{~mL}$. Can J Anesth 2011; 58: 1001-6.

8. Renes SH, Rettig HC, Gielen MJ, et al. Ultrasound-guided lowdose interscalene brachial pleuxus block reduces the incidence of hemidiaphragmatic paresis. Reg Anesth Pain Med 2009; 34: 498502.

9. Ip VH, Tsui BC. Continuous interscalene block: the good, the bad and the refined spread. Acta Anaesthesiol Scand 2012; 56: 52630.

10. Alexander B, Angaramo G, Walz JM, et al. A novel approach to managing trans-subclavian transcatheter aortic valve replacement with regional anesthesia. J Cardiothorac Vasc Anesth 2018; 32 : 1391-3.

11. Block M, Pitchon DN, Schwenk E, et al. Left subclavian transcatheter aortic valve replacement under combined interscalene and pectoralis nerve blocks: a case series. A A Pract 2018; 11: 332-5. 
12. Ciechanowicz S, Patil V. Lipid emulsion for local anesthetic systemic toxicity. Anesthesiol Res Pract 2012; DOI: https://doi. org/10.1155/2012/131784
Publisher's Note Springer Nature remains neutral with regard to jurisdictional claims in published maps and institutional affiliations. 